\title{
Assessment of 3D Short Crack Closure in Ti-6Al-4V Alloy Utilizing Synchrotron X-ray Microtomography
}

\author{
Valary TUBEI ${ }^{* 1}$, Meysam HASSANIPOUR $^{1}$, Kyosuke HIRAYAMA ${ }^{1}$, Hiroyuki TODA ${ }^{1}$ \\ Akihisa TAKEUCHI ${ }^{2}$ and Kentaro UESUGI ${ }^{2}$ \\ ${ }^{1}$ Department of Mechanical Engineering, Kyushu University, 744, Motooka, Nishi Ward, Fukuoka, Fukuoka 819-0395, Japan \\ 2 Japan Synchrotron Radiation Research Institute, 1-1-1, Kouto, Sayo Cho, Sayo Gun, Hyogo 679-5148, Japan
}

\begin{abstract}
$\underline{\text { Abstract }}$
Synchrotron X-ray microtomography was utilized to observe the complex 3D crack morphology and the closure behavior of a short crack in Ti-6Al-4V alloy. The aim of the study was to investigate the effect of the crack path evolution on the $3 \mathrm{D}$ short crack closure behavior. In situ fatigue tests at $\mathrm{R}=0.1$ were carried out using microtomography with a spatial resolution of $1 \mu \mathrm{m}$. The 3D crack morphology was observed in detail consisting of non-facets (zigzag), branching, and facets with deflection angles indicating the presence of mode II and mode III displacements. The crack grows with facet-like paths mainly in a grains as compared to the non-facet paths in the $\alpha+\beta$ grains. The change in the crack path from facet-like paths to non-facet-like paths in the larger crack front induces an increase in the fractional area of closed patches.
\end{abstract}

Key words: Short crack, crack closure, microtomography, synchrotron radiation, and volume rendering.

\section{Introduction}

Fatigue crack closure has been identified as the predominant factor controlling the crack growth rates via reducing the effective driving force needed for crack propagation [1-2]. Traditionally, studies have estimated an average of crack closure along the crack front by using experimental methods such as clip gauges [2]. However, there is a local variation in crack closure through specimen's thickness which can only be taken into account by the use of destructive approaches [3]. Therefore, there is a need to quantify the crack closure along the crack front using non-destructive techniques. As a result, recently X-ray tomography, which enables the visualization of the $3 \mathrm{D}$ crack front and the microstructure, has been utilized to study $3 \mathrm{D}$ crack closure behavior. By using this technique, a variety of local crack paths along the crack front with their respective closure behavior can be quantified within one specimen.

By employing X-ray tomography, Toda et al. tracked particles inside an aluminum alloy to obtain local crack opening displacement along a large crack front [4]. In their study, they were able to clarify that the loss of crack surface contact is progressive and a single opening load level could not be defined. Moreover, they found out that the closure behavior was strongly influenced by mode III displacement associated with the local crack morphology [5]. A separate study by Limodin et al. reported that the non-uniform distribution of closure along the crack front generates unsymmetrical crack propagation rates [6]. However, the effect of the short crack path morphology and its evolution on crack closure behavior has not been evaluated.

In this study, synchrotron X-ray microtomography has been utilized to observe the 3D crack closure behavior in a short crack in Ti-6Al-4V alloy. The observation of the complex crack morphology and the crack front geometry was carried out at a spatial resolution of $1 \mu \mathrm{m}$. The fractional area of closed patches is quantified for the short crack at two different crack fronts. The effect of the crack paths evolution on those closed patches is further analyzed.

\section{Material and experiments}

The material used in this study was Ti-6Al-4V alloy. From an initial thickness of $10 \mathrm{~mm}$, the alloy was hot rolled at $800{ }^{\circ} \mathrm{C}$ and the thickness was reduced by $50 \%$. After this, it was tempered for 96 hours at $900^{\circ} \mathrm{C}$ in a furnace and allowed to cool inside the furnace. A bimodal structured Ti-6Al-4V alloy with the composition of $65 \%$ a-phase and $35 \% \beta$-phase was obtained after the heat treatment. Specimen for the study was then cut out from the heat treated material using EDM machine and notch of $(60 \times 20 \times 4) \mu \mathrm{m}$ made at the specimen's square cross-section of $(600 \times 600) \mu \mathrm{m}$. Fatigue test was then done at $\mathrm{R}=0.1$ with a maximum stress of $622 \mathrm{MPa}$ and the crack was allowed to grow to a surface length of about $160 \mu \mathrm{m}$. 
In situ computed microtomography was carried out at the BL20XU beamline in SPring-8, a synchrotron radiation facility in Hyogo, Japan. The material test rig was positioned $80 \mathrm{~m}$ from the X-ray source with the X-ray beam having photon energy of $30 \mathrm{keV}$. A CCD detector of $2048 \times 2048$ pixels was positioned $53 \mathrm{~mm}$ behind the sample. Scanning was performed at load levels starting from $10 \%$ to $100 \%$ of the applied load with load increments of $10 \%$. At each stage, 1800 radiographs scanning $180^{\circ}$ capturing the whole specimen's cross-section were taken with the exposure time of $150 \mathrm{~ms}$ for each scan. The sample was then cycled to a crack length of $227 \mu \mathrm{m}$. The same imaging procedure for the crack of crack length $160 \mu \mathrm{m}$ was repeated for the $227 \mu \mathrm{m}$ long crack to obtain the projections.

The images were then reconstructed from the obtained series of projections. After the reconstruction, they were converted to 8-bit images which have better contrast between $\alpha$ and $\alpha+\beta$ phases compared to the reconstructed images. The $2 \mathrm{D}$ slice images were then volume rendered to obtain a 3D image of the scanned section. The 3D images for each load level were matched to have the same location of the notch for accurate analysis of the local crack closure level. A linear attenuation coefficient range was carefully selected to separate the crack from the material. The crack surface was then extracted for every load level using the seed growth technique. For the evaluation of COD, the crack was binarized and the crack images' Cartesian coordinates converted to polar coordinates. Additional details of the methods used can be found in the paper by Hassanipour et al. on the behavior of short crack growth and interaction with 3D microstructure [7].

\section{Results and discussion}

\subsection{Crack morphology}

The complex morphology of the 3D cracks for two crack fronts that will be hereafter referred to as their crack lengths on the surface of $160 \mu \mathrm{m}$ and $227 \mu \mathrm{m}$, are visualized in detail in Fig.1. The 3D crack morphology consists of facet paths, non-facet or zigzag paths, and crack bifurcation. The crack fronts for both crack lengths have irregular shapes implying the strong interaction of the crack with the local microstructure. Crack growth on the surface and inside the alloy varies along the crack front line. Birosca et al. reported that favorable grain orientations may lead to higher crack growth while some features such as grain boundaries can impede growth [8].
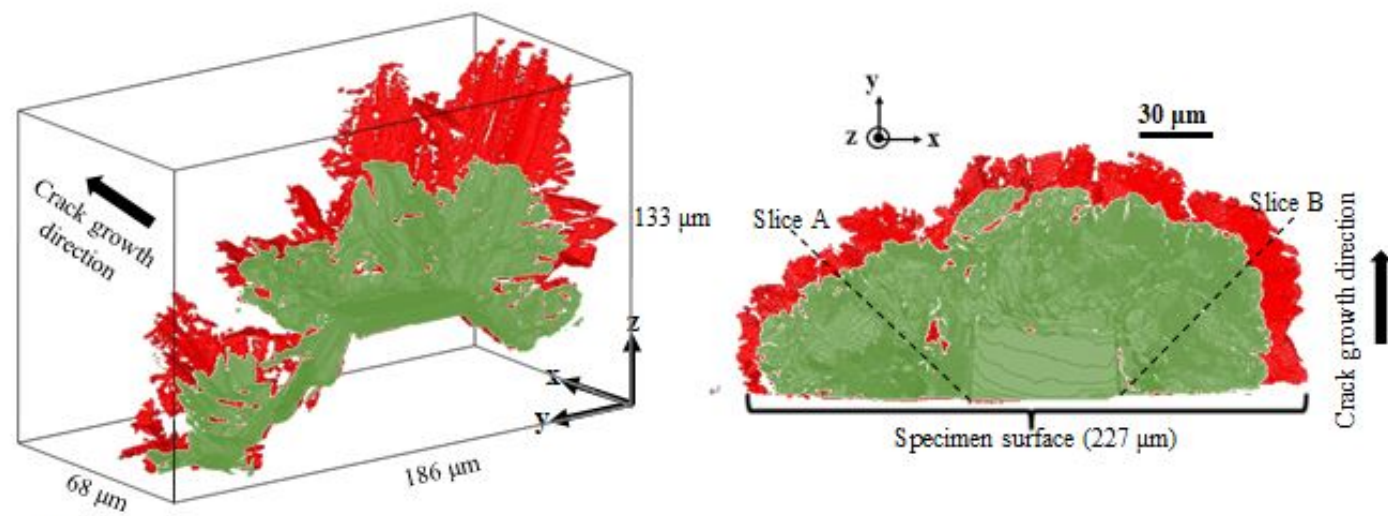

(a)

(b)

Crack length $227 \mu \mathrm{m} \quad$ Crack length $160 \mu \mathrm{m}$

Fig. 1 Three dimensional visualization of the extracted fatigue crack surfaces at $100 \%$ of applied load. (a) Three dimensional crack surface of crack length $160 \mu \mathrm{m}$ superimposed on the crack surface of the $227 \mu \mathrm{m}$ crack length showing the crack's complex morphology and the variation in growth followed by (b) the superimposed crack surfaces projected on the $X Y$ plane.

The crack paths on the left side of the notch consist mainly of long facet-like paths with lower changes in the deflection angles through the grains. As a result, the crack growth on the left side of the notch is higher than on the right side at $160 \mu \mathrm{m}$ length. Previous studies corroborate the observation that the growth rate of facet-like paths is higher than those of non-faceted paths [7, 9]. In contrast, the larger crack at $227 \mu \mathrm{m}$ as seen in Fig.1 (a) has higher crack growth on the right side of the notch than on the left. This is due to the change in crack path morphology from $160 \mu \mathrm{m}$ to 227 
$\mu \mathrm{m}$ which can be clarified by using cross-sectional slice images A and B shown in Fig.1 (b). These cross sectional slices are shown in Fig. 2 at $160 \mu \mathrm{m}$ and $227 \mu \mathrm{m}$ crack surface lengths.

In Fig.2 (a) the crack path changes from mainly facet-like paths at $160 \mu \mathrm{m}$ to branching at $227 \mu \mathrm{m}$ as it grows through $a+\beta$ grain as seen in Fig.2 (b) which impedes crack growth. It has been shown that crack branching reduces the crack driving forces at the crack tip [1, 10]. On the other hand, the crack in Fig.2 (c) grows to $227 \mu \mathrm{m}$ with a small deflection and continues to grow with a facet-like path as shown in Fig.2 (d). The low change in the crack deflection angle may be the reason for the high growth.

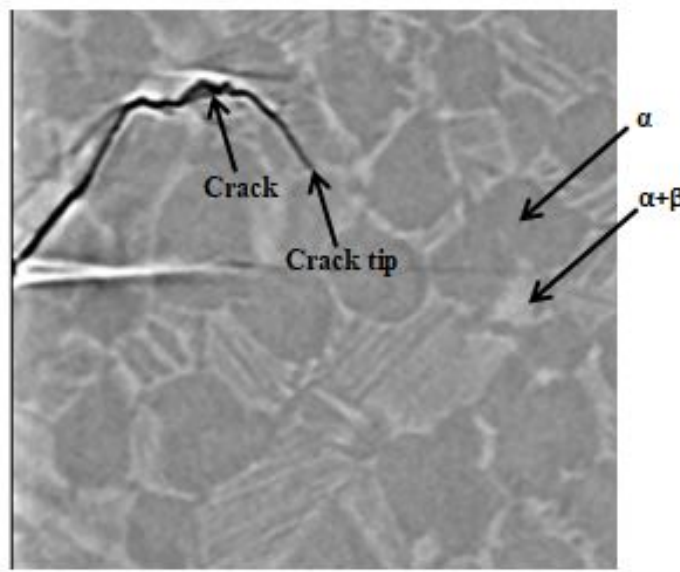

(a)

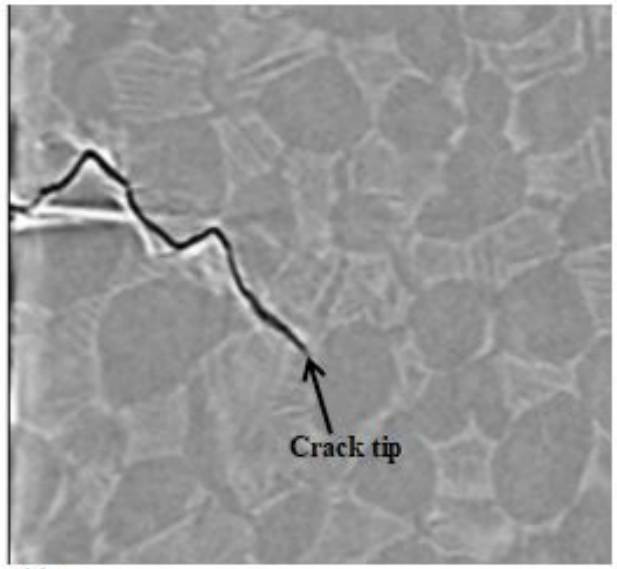

(c)

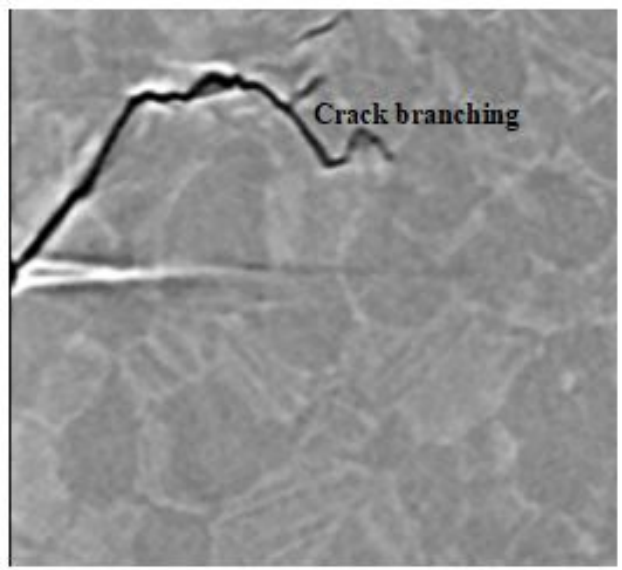

Slice A

(b)

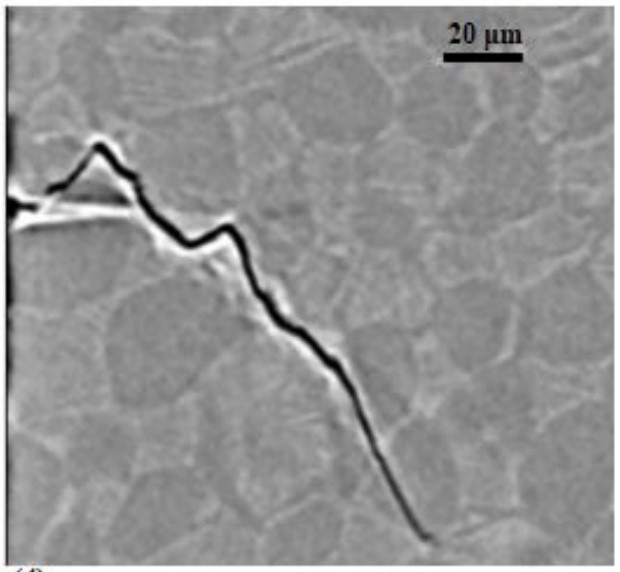

(d)

Fig. 2 Cross sectional slice images projected on the XZ plane at maximum load. (a) and (b) correspond to cross sectional slices at crack lengths at $160 \mu \mathrm{m}$ and $227 \mu \mathrm{m}$ respectively on the left side of the notch followed by (c) and (d) on the right side of the notch.

3.2 Crack closure behavior 


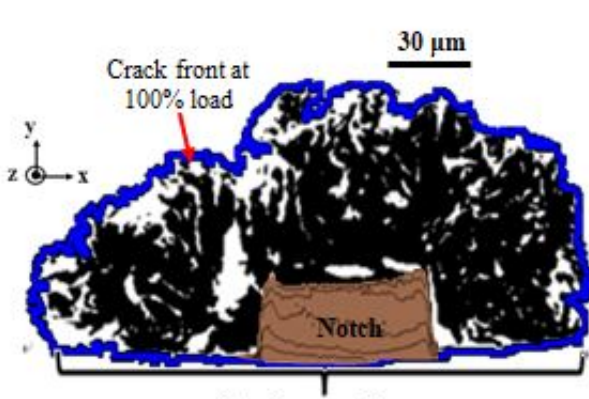

(a)
Specimen surface
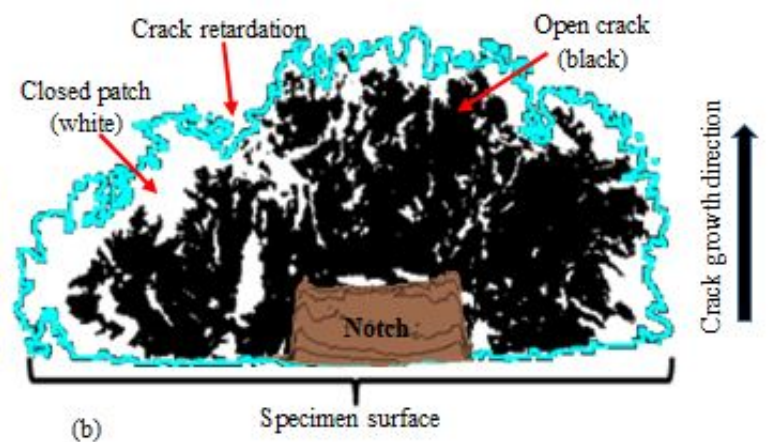

(b)

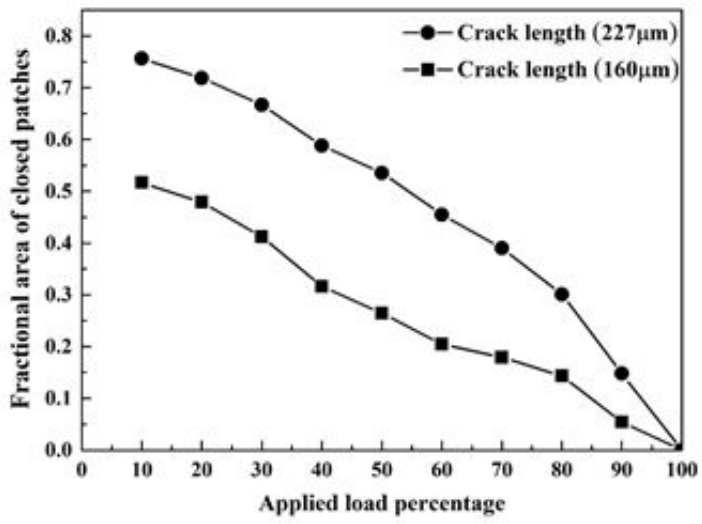

(c)

Fig. 3 Crack closure behavior with respect to crack front propagation. The binarized projected crack surfaces on the XY plane are shown in (a) and (b) that emphasize the spatial distribution of the closed patches (white) at $40 \%$ of the applied load superimposed on the crack front at the $100 \%$ load for the short crack at $160 \mu \mathrm{m}$ and $227 \mu \mathrm{m}$ lengths respectively. In (c) the fractional area of closed patches for the two short crack lengths are shown.

Fig.3 (a) and (b) are the projected crack surface (black) at $40 \%$ of the applied load superimposed with the crack front at $100 \%$ load at $160 \mu \mathrm{m}$ and 227 $\mu \mathrm{m}$, respectively to show the distribution of the closed patches (white). The closed patches close to the crack front are mainly due to plasticity at the crack tip and those behind the tip may be due to contact of asperities on the crack faces. The different crack path morphologies that arise from the crack's interaction with microstructure leads to the variation of the distribution of these contact points on the crack surfaces. The increase in the plastic zone size induces higher near-tip closure. As a result, in Fig. 3 (b) more contact points close to the crack front are seen in comparison to those in Fig. 1 (a).

The fractional area of closed patches increases with a decrease in the load as shown in Fig. 3 (c). The increase in the crack front size that has larger plastic zone sizes as explained earlier, leads to the higher fraction of closed patches observed for the $227 \mu \mathrm{m}$ crack length as compared to that of the $160 \mu \mathrm{m}$. The inhomogeneous distribution of the closed patches that was observed in Fig.3 (a) and (b) contributes to the variation of the fractional area of closed patches from one load level to another that is seen in Fig.3 (c).

\subsection{Local crack closure}

In order to observe the increase in the local contact points from $100 \%$ to $10 \%$ load, the fraction of contact points for the crack paths in slice A and slice $B$ at $160 \mu \mathrm{m}$ and $227 \mu \mathrm{m}$ lengths were quantified. The results are shown in Fig.4 where a fraction equal to 1 implies that the crack faces are fully in contact, otherwise the crack is still open at some locations within the measured distance from the crack tip. The crack opening at the tip of slice A was 
higher than that of slice B due to the path with long facets and few deflections. As a result, at the surface crack length of $160 \mu \mathrm{m}$ in Fig. 4 (a), the crack in slice A has lower fractions of closed points with decrease in the load in comparison to those in slice B.

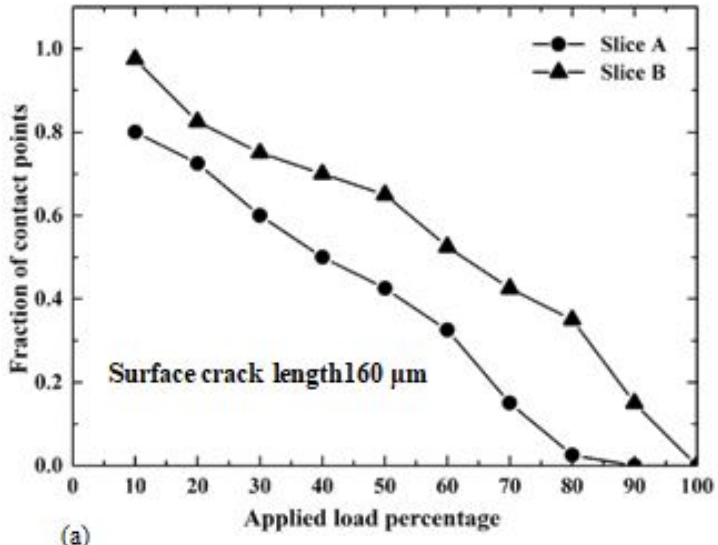

(a)

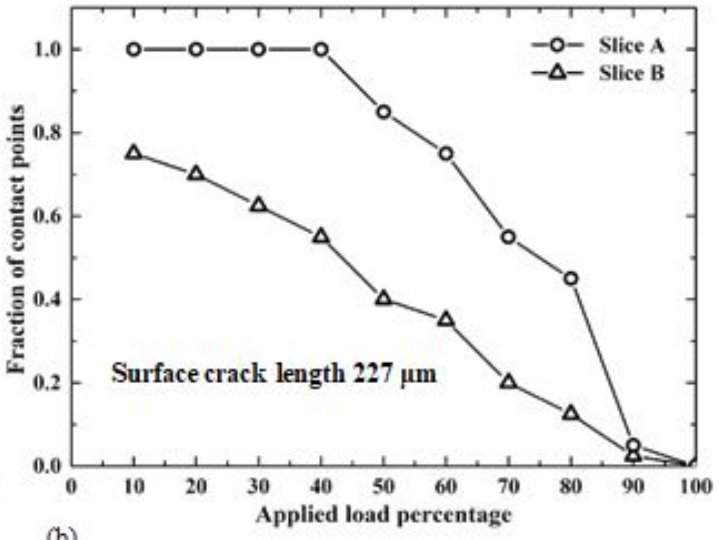

(b)

Fig.4 Local variation of crack contact points with crack path morphology. The fraction of contact points for cracks in slices A and B at surface crack length of $160 \mu \mathrm{m}$ are shown in (a) followed by (b) at $227 \mu \mathrm{m}$.

The behavior of the fraction of closed points for the crack paths in slices A and B changes with crack path evolution as shown in Fig.4 (b) at $227 \mu \mathrm{m}$. The crack path in slice A changes from facet-like at $160 \mu \mathrm{m}$ to branching at $227 \mu \mathrm{m}$ and as a result, there is an increase in the fraction of closed points than the crack in slice B. The crack in slice A fully closes at $40 \%$ load implying that branching close to the crack tip can significantly increase the fraction of contact points resulting in a reduction in the crack tip opening. This shows that the crack tip behavior significantly affects the subsequent crack's behavior. Slice B has a low deflection angle as it grows to $227 \mu \mathrm{m}$ and continues to grow with a facet-like path. This could be the reason for the low number of contact points seen in Fig.4 (b).

\section{Conclusion}

In situ computed microtomography with a spatial resolution of $1 \mu \mathrm{m}$ was employed to investigate the crack closure behavior in Ti-6Al-4V alloy. The complex morphology of the crack was observed including the crack front geometry, the crack paths such as facets, non-facets and regions of branching. The inhomogeneous crack fronts indicated the strong influence of the microstructure. First, it was observed that the crack growth strongly depends on crack path morphology. The paths that mostly consist of facets have a high growth as compared to non-facet paths. Secondly, the near-tip closure increases due to the larger plastic zone size. Moreover, the crack path evolution from facet-like to non-facet-like paths leads to an increase in the number of contact points at the crack front. From the findings of the study, the near-front crack behavior can change the crack's behavior.

\section{Acknowledgement}

The synchrotron radiation experiments were performed at SPring-8 with the approval of Japan Synchrotron Radiation Research Institute through proposal number 2017A0076 and 2018A0076. This work was supported through the grant-in-aid for scientific research from Structural Materials for Innovation (SM41) of the Cross-ministerial Strategic Innovation Program (SIP) and Light Metals Education Foundation.

\section{References}

[1] S. Suresh, Eng. Fract. Mech. 18 (1983) 577-593

[2] W. Elber, Eng. Fract. Mech. 2 (1970) 37-44.

[3] J. Telesman, D. M. ASTM STP 982, (1998) 568-582

[4] H.Toda, L. Sinclair, J.Y. Buffière et al. Philos. Mag. 21 (2003) 2429-2448. 
[5] H.Toda, S. Yamamoto, M. Kobayashi et al. Acta Mater. 56 (2008) 6027-6039.

[6] N. Limodin, J. Réthoré, J.Y. Buffière et al. Acta Mater. 58 (2010) 2957-2967.

[7] M. Hassanipour, S.Watanabe, K.Hirayama et al. Mater Sci and Eng. 738 (2018) 229-237.

[8] S. Birosca, J.Y. Buffière, M. Karadge et al. Acta Mater. 59 (2011) 1510-1522.

[9] C.M Ward-Close, C. J. Beevers, Metall. Trans. 11 (1980) 1007-1017.

[10] H. kitagawa, R. Yuuki, T. Ohira, Eng. Fract. Mech. 7 (1975) 515-529. 